\title{
Assessment of Orthodontist's Prospects and Acquaintance Regarding Miniscrew Implants
}

\author{
Janagarathinam V.A. ${ }^{1}$, Veerasankar S², Shahul Hameed Faizee K.M. ${ }^{3}$, Piradhiba R ${ }^{4}$, Navaneetha Nambi ${ }^{5}$ \\ 1, 2, 3, 4, 5 Department of Orthodontics and Dentofacial Orthopaedics, Sathyabama \\ Dental College and Hospital, Semmancheri, Chennai, Tamil Nadu, India.
}

\section{ABSTRACT}

\section{BACKGROUND}

Globally there has been an increase in the usage of miniscrew implants (MSI) because it expanded the envelope of discrepancy which led to the management of most severe cases without surgery. There is limited data available about awareness and usage of MSI among Indian orthodontists. So, the purpose of this study was to evaluate the Indian orthodontists' experiences regarding MSI.

\section{METHODS}

The study sample consisted of 1000 qualified orthodontists practicing in India. The present study was a questionnaire-based survey, circulated among the orthodontists through Google forms. The questionnaire included both close-ended and selfadministered questions. The data was analysed using the statistical analysis SPSS software version 20.0.

\section{RESULTS}

Out of 2000 circulated Google forms there was $50 \%$ response rate. Among the participants, $95.7 \%$ had attended training for MSI placement. Among the participants who attended training, $81.1 \%$ were using mini screw in practice, of whom $60 \%$ participants had placed more than 50 implants. Most participants (70.9\%) recommended insertion torque of $5-10 \mathrm{Nm}$ and for the time of force application, $48.6 \%$ go with force application immediately after placement. Most participants (75.7 \%) were satisfied with MSI usage.

\section{CONCLUSIONS}

There has been an increase in the usage of MSI among the Indian orthodontists. The knowledge, awareness and experience about MSI among Indian orthodontists was in accordance with recent global trends. The failure rate experienced by Indian orthodontists was similar to orthodontists practicing globally.

\section{KEY WORDS}

Mini Screw Implants (MSI), Orthodontists, Survey, India
Corresponding Author:

Dr. V. A. Janagarathinam,

Department of Orthodontics and

Dentofacial Orthopaedics,

Sathyabama Dental College and Hospital,

Semmancheri, Chennai,

Tamil Nadu, India.

E-mail: janagarathinamva@gmail.com

DOI: $10.14260 / \mathrm{jemds} / 2021 / 256$

How to Cite This Article:

Janagarathinam VA, Veerasankar S, Faizee SHKM, et al. Assessment of orthodontist's prospects and acquaintance regarding miniscrew implants (MSI). J Evolution Med Dent Sci 2021;10(17):1197-1202, DOI: $10.14260 / \mathrm{jemds} / 2021 / 256$

Submission 20-12-2020,

Peer Review 25-02-2021,

Acceptance 02-03-2021,

Published 26-04-2021.

Copyright (c) 2021 Janagarathinam V.A. et al. This is an open access article distributed under Creative Commons Attribution License [Attribution 4.0 International (CC BY 4.0)] 


\section{BACKGROUND}

Daskalogiannakis defined anchorage as "resistance to unwanted tooth movement". Adequate anchorage control is fundamental for successful orthodontic treatment. Conventionally, orthodontists have used intraoral appliances and extraoral appliances to control anchorage and achieve required tooth movement. Based on Newton's third law, anchorage units experience an equal and opposite force. Negating this reciprocal force has been and still in focus, emphasising the need for biomechanical considerations and research in orthodontics. The evolution of temporary anchorage devices was based on the development and improvement of traditional orthodontic anchorage, dental implants and orthognathic fixation methods. Later, modifications of these techniques were unified with basic biologic and biomechanical principles of osseointegration into orthodontic mechanics that were finally improved based on experiences with interdisciplinary dentistry. ${ }^{1}$

Miniscrew implants is a bone-based anchor referred to as temporary anchorage devices (TADs). This form of anchorage has been widely accepted by the profession and has provided a facility for orthodontists to widen their clinical scope of appliance therapy. ${ }^{2}$

Recently, arising importance on the miniscrew implant type of TADs. Miniscrew implants have been used as anchorage for tooth movements that could not otherwise have been performed such as, patients with insufficient teeth for the application of conventional anchorage, cases where the forces on the reactive units would generate adverse side effects and patients with a need for asymmetrical tooth movements in all planes of space. Technical advances in miniscrew implant design have led to a decrease in discomfort and chair time during their placement and avails the increase in the envelope of discrepancy which leads to the management of most severe cases without surgery. ${ }^{3}$

The miniscrew implants are available at various design based upon the manufacturer's specifications. The advantage of MSI was, its insertion and removal does not require any specific surgical procedure. In contrast with other means available such as orthodontic implants, miniplates and onplants, that require flap surgery, MSI can be easily inserted chair side as there is no need for any complicated clinical and laboratory procedures. In case of absolute anchorage, MSI offers a variety of locations where it can be easily applied and removed. However, this has certain drawbacks like failure during and after placement due to material used, technique sensitivity and biological factors. ${ }^{4}$ Hence orthodontists have mixed opinions on the usage of temporary anchorage devices.

So, this study was done to assess the orthodontist's prospects and acquaintance regarding MSI usage in orthodontic practices, based on a survey.

\section{METHODS}

The study protocol was approved by the institutional review board of Sathyabama Institute of Science and Technology (IBSC). The participants participated voluntarily, and informed written consent was obtained. They were assured that no personal information would be shared and their data would be kept confidential.

This survey was based on a questionnaire circulated among 2000 Indian orthodontists. Study period was from June 2020 to December 2020. They were asked to participate in the study by an invitation letter distributed via internet (E-mail or social media). An online questionnaire using Google forms was used to collect the data. The validity and reliability of the questionnaire was accessed. This recollection, experience and opinion-based questionnaire was divided into 3 sections:

1. Practice characteristics: which includes zone of practice, gender distribution, clinical experience and nature of practice.

2. MSI experience: which includes training attended, number of MSI placed, recommended insertion torque, time of force application, material of choice, preplacement patient anxiety assessment, preferred MSI systems, soft tissue overgrowth and recommended oral hygiene measures.

3. MSI complications: which includes cause and rate of failures and post failure management.

\section{Statistical Analysis}

Data were analysed using SPSS software version 20.0 and depicted in terms of percentages. Blinded, annotated data were extracted for statistical analysis. Cross-tabulations were performed as appropriate and the significance of observed differences was assessed by means of chi-square test. The level of significance was set at $\mathrm{P}<0.05$.

\section{RESULTS}

The study population comprised of 2000 eligible orthodontists throughout India and questionnaire was circulated as Google forms, out of which there was a $50 \%$ response rate. The questionnaires were divided in to three categories as follows,

\section{Practice Characteristics}

Among the participants, $57.3 \%$ were from South India and $42.7 \%$ were from North India, which comprised of $55.6 \%$ males and $44.4 \%$ females. Respondents' clinical experience was categorised, and the $\%$ of participants was $54.2 \%$ for 6 15 years, $34.8 \%$ for 0 - 5 years and $10 \%$ for $16-25$ years and $1 \%>25$ years. Nature of practice of respondents were categorised in which $50 \%$ participants involved only in private practice, $30.2 \%$ in both private practice and institution, $10.4 \%$ in government institution, $8.8 \%$ in private institutions and $0.6 \%$ not responded.

\section{MSI Experience}

Among the respondents $59 \%$ have attended live hands-on course using typodont or 3D printed models, $26.9 \%$ attended only courses with live demo, $9.8 \%$ attended only lectures, 3.5 $\%$ did not attend any specialization course and $0.8 \%$ did not respond. Regarding the experience of MSI usage in practice, $59.5 \%$ of them were using MSI for more than 5 years, $16.9 \%$ for 2 - 5 years, $4.7 \%<1$ year, $18.9 \%$ not using MSI in their 
practice; among the respondents using MSI, $37.7 \%$ have placed 50 - 100 MSI, $21.8 \%$ placed < 50 MSI, $16.4 \%$ placed $100-200$ MSI, $5.2 \%$ placed $>200$ MSI and $18.9 \%$ not responded.

On assessment of the number of MSI placed by the respondents in past one year, $72.8 \%$ placed $1-20$ MSI, $5.4 \%$ placed 21 - 50 MSI and $1.9 \%$ placed $>50$ MSI, $0.8 \%$ have not placed MSI in past 1 year and $19.1 \%$ not responded; Regarding the usage of placement guide by the respondents, $4.3 \%$ of orthodontists always used it, $15.6 \%$ used them mostly, whereas $34.7 \%$ of respondents used it occasionally, $25.5 \%$ of them never used the placement guide and $19.9 \%$ failed to respond. Regarding insertion torque during MSI placement, $70.9 \%$ have recommended $5-10 \mathrm{Nm}, 4.6 \%$ recommended < $5 \mathrm{Nm}, 4.0 \%$ recommended $10-15 \mathrm{Nm}, 0.4 \%>15 \mathrm{Nm}$ and $20.1 \%$ not responded.

Regarding the time of force application after placement, $48.6 \%$ engaged force immediately after placement, $26.4 \%$ after 3 weeks, $5.3 \%$ after 1 month, $19.7 \%$ have not responded; Among MSI users, $64.7 \%$ have titanium as material of choice, $14.4 \%$ have stainless steel as material of choice, $20.9 \%$ have not responded; On assessment of pre-placement patient anxiety by MSI users, $39.0 \%$ have rated mild, $24 \%$ as moderate and $3.1 \%$ very high. $13.5 \%$ users stated that patient does not encounter pre-placement anxiety and $20 \%$ have not responded; Most respondents (67\%) graded treatment outcome using MSI as satisfied, $8.7 \%$ very satisfied, $4.4 \%$ dissatisfied and $0.3 \%$ very dissatisfied, $19.6 \%$ have not responded.

Among various available MSI systems, $24.2 \%$ of MSI users have preferred American Orthodontics, $15.1 \%$ Ormco, $13.4 \%$ 3M, $6.0 \%$ other's, $5.6 \%$ SK surgical, $5.1 \%$ Dentos, $3.0 \%$ Favanchor, $2.3 \%$ of JJ, $1.4 \%$ Bioray, $1.2 \%$ Orthosystem, $0.9 \%$ Leone and Dentarum, $0.6 \%$ Biomed and $20.3 \%$ not responded; Regarding soft tissue over growth around MSI after placement, $33.7 \%$ have experienced $<25 \%$ of soft tissue over growth around MSI, $32.9 \%$ experienced $25-50 \%$ of soft tissue over growth, $0.3 \%$ experienced $>50 \%$ of soft tissue over growth, $11.7 \%$ not experienced any and $21.4 \%$ have not responded; Regarding oral hygiene instructions after MSI placement, $35.4 \%$ of the respondents have been recommending oral hygiene measures but not specified, 24.0 $\%$ recommends mouth wash, $14.8 \%$ have not recommended any and $20.4 \%$ not responded.

\section{MSI Complications}

Regarding MSI failure after placement, $32.8 \%$ have experienced equal proportion in both jaws, $23.8 \%$ only in maxilla, $17.9 \%$ only in mandible and $3.9 \%$ not experienced any failure and $21.6 \%$ not responded; decision after MSI failure, depends on clinical situation for $38.1 \%$ of participants, $15.8 \%$ replace with new implant, $14.6 \%$ drop the idea of treating with MSI, $9.3 \%$ replace the same MSI, $22.2 \%$ not responded; regarding MSI failure rate, $37.6 \%$ experience a failure rate of $10-25 \%, 28.3 \%$ experience a failure rate of 25 - $50 \%, 9.8 \%$ experience a failure rate of $<10 \%, 2.2 \%$ experience a failure rate of $>50 \%$ and $22.1 \%$ not responded.

The common cause for MSI failure was loosening on the following appointment for $50.3 \%$, root contact for $13 \%$, fracture during placement for $5.6 \%$, bending of MSI for $4.7 \%$ and $26.4 \%$ not responded.

\section{Relationships among Response}

\begin{tabular}{|c|c|c|c|c|}
\hline \multicolumn{5}{|c|}{ Experience of Orthodontists (in Years) } \\
\hline $\begin{array}{l}\text { Decision after } \\
\text { MSI failure }\end{array}$ & $0-5$ & $6-15$ & $16-25$ & $>25$ \\
\hline $\begin{array}{l}\text { Depends on the } \\
\text { clinical } \\
\text { situation }\end{array}$ & $76(21.8 \%)^{* * *}$ & $253(46.7 \%)^{* * *}$ & $45(45 \%)^{* *}$ & $7(70 \%)^{* *}$ \\
\hline \multicolumn{5}{|c|}{ Table 1. Decision after MSI Failure } \\
\hline
\end{tabular}

The relation between years of experience as an orthodontist and decision after MSI failure is statistically very highly significant. From Table 1 it is evident that among the MSI users $70.0 \%$ with $>25$ years of experience, $46.7 \%$ with $6-15$ years of experience, $45.0 \%$ with 16 - 25 years of experience and $21.8 \%$ of the respondents with $0-5$ years of experience, have taken decision based on clinical situation in MSI failures.

\begin{tabular}{|c|c|c|c|c|}
\hline \multicolumn{5}{|c|}{ Experience of Orthodontists (in Years) } \\
\hline $\begin{array}{l}\text { Treatment } \\
\text { outcome } \\
\text { using MSI }\end{array}$ & 0 - 5 years & $6-15$ years & $16-25$ years & $>25$ years \\
\hline Satisfied & $157(45.1 \%)^{* *}$ & $425(78.4 \%)^{\cdots}$ & $84(84.0 \%)^{\cdots \cdots}$ & $\begin{array}{l}5(50.0 \%) \\
\text { very satisfiec }\end{array}$ \\
\hline \multicolumn{5}{|c|}{ Table 2. Treatment Outcome Using MSI } \\
\hline$* * \mathrm{P}$-value $<$ & & & & \\
\hline
\end{tabular}

The relation between years of experience as an orthodontists and satisfaction of treatment outcome is statistically very highly significant. From Table 2 it is evident that $84.0 \%$ of the respondents were satisfied with MSI treatment outcome with 16 - 25 years of experience as orthodontist, $78.4 \%$ of the respondents were satisfied with 6 - 15 years of experience, $50.0 \%$ of the respondents were very satisfied with $>25$ years of experience and $45.1 \%$ of the respondents were satisfied in $0-5$ years of experience as orthodontists.

\begin{tabular}{|c|c|c|c|}
\hline \multicolumn{4}{|c|}{ Years of Using MSI } \\
\hline $\begin{array}{l}\text { Decision after MSI } \\
\text { failure }\end{array}$ & Less than 1 year & $2-5$ years & More than 5 years \\
\hline $\begin{array}{l}\text { Depends on the } \\
\text { clinical situation }\end{array}$ & $13(27.7 \%)^{* * *}$ & $78(46.2 \%)^{* * *}$ & $290(48.7 \%)^{* * *}$ \\
\hline \multicolumn{4}{|c|}{ Table 3. Decision after MSI Failure } \\
\hline *P-value $<.001$ & & & \\
\hline
\end{tabular}

The relation between years of using MSI and decision after MSI failure is statistically very highly significant. From Table 3 it is evident that $48.7 \%$ of the respondents with $>5$ years of using MSI, $46.2 \%$ of the respondents with $2-5$ years of using MSI and $27.7 \%$ of the respondents with less than 1 year using MSI have taken decision based on clinical situation in MSI failures.

\begin{tabular}{|c|c|c|c|c|}
\hline \multicolumn{5}{|c|}{ Years of Practicing Orthodontics } \\
\hline $\begin{array}{c}\text { Reason for most } \\
\text { common MSI } \\
\text { failure }\end{array}$ & $0-5$ & $6-15$ & $16-25$ & $>25$ \\
\hline $\begin{array}{l}\text { Loosening on the } \\
\text { following } \\
\text { appointment }\end{array}$ & $93(26.7 \%)^{\cdots *}$ & $330(60.9 \%)$ & $73(73.0 \%)^{* * *}$ & $7(70.0 \%)^{* *}$ \\
\hline \multicolumn{5}{|c|}{ Table 4. Reason for Most Common MSI Failure } \\
\hline
\end{tabular}


The relation between years of practicing orthodontics and reason for MSI failure is statistically very highly significant. From Table 4 it is evident that $73.0 \%$ of the respondents with 16 - 25 years of experience as orthodontist, $70 \%$ of the respondents with $>25$ years of experience, $60.9 \%$ of the respondents with 6 - 15 years of experience and $26.7 \%$ of the respondents with 0 - 5 years of experience as orthodontist have loosening of MSI on the following appointment as a reason for MSI failure.

\section{DISCUSSION}

\section{Practice Characteristics}

Questionnaire-based survey was circulated among the 2000 Indian orthodontists through Google forms. Among 2000 circulated Google forms about $50 \%$ of the orthodontists have responded to the survey and informed written consent was obtained from all participants. This response was much higher compared to the response rate of $7.7 \%$ and $6 \%$ in a study conducted by Keim RG et al. ${ }^{5}$ and Buschang PH et al. ${ }^{6}$

\section{MSI Experience}

In our survey $95.7 \%$ of the participants have reported that they received training for MSI placement. In a similar survey done by Hyde JD et al. ${ }^{7}$ reported that $12.8 \%$ of American orthodontists received training for MSI placement. However, this survey was completed before 2010 and it was probable that orthodontists were interested in receiving more training as the usage of MSI have become more established.

The proportion of orthodontists using mini screw in practice was $81.1 \%$ which is comparatively higher when compared to the results (57\%) of the similar study done by Shetty S et al. ${ }^{8}$ in 2019. Most of the participants (59.5\%) are using MSI for more than 5 years.

In our survey, participants who attended training for MSI placement was $95.7 \%$ but who were implementing MSI in their practice was only $81.1 \%$. The reason for not using MSI in their practice after training may be due to fear of risk factors or patient refusal as supported by a survey by Ahmed Meeran et al. ${ }^{9}$ concluding that Indian orthodontists did not use MSI mainly due to fear of risk factors (54\%) and patient refusal (29\%).

In a study done by Buschang et al. ${ }^{6}$ in 2008 among American orthodontists, the majority (57.4\%) of participants had only placed 10 or fewer MSI, similar to Barthelemi and Beauval's ${ }^{10}$ study in 2015 among French orthodontists, in which $65 \%$ of MSI users had treated lesser than 10 patients. In the present study, there was high number of respondents who had placed more than 50 MSI (60.3\%), which makes sense as the previous studies were completed in 2008 and 2015, the trend has been towards an increase in MSI usage among the orthodontists.

Optimal positioning has always been a critical factor for the effectiveness and success of miniscrew implants. A surgical guide provides three-dimensional surgical bur control, for accurate placement of MSI, at the desired location and angle. ${ }^{11}$ In our survey, 546 respondents used a surgical guide for MSI placement, which is comparatively higher to the response rate of (463) participants using surgical guide for MSI placement, in a survey done by Ahmed Meeran et al. ${ }^{9}$ among the Indian orthodontists.

Most respondents (70.9 \%) recommended insertion torque of $5-10 \mathrm{Nm}$ which is in agreement with the studies done by Motoyoshi et al. ${ }^{12}$ which concludes that minimum insertion torque (MIT) in maxilla and mandible is $5-10 \mathrm{Nm}$ for higher success rates than MIT $>10$ or $<5 \mathrm{Nm}$.

Among the participants $48.6 \%$ applied force immediately. These results were in accordance with the study done by Chen Y et al. ${ }^{13}$ in 2009 and by Jambi S et al. ${ }^{14}$ in 2014.

In the present survey, majority of Indian orthodontists (75.7\%) were satisfied or very satisfied with their MSI treatment outcomes. In a similar survey distributed to American orthodontists, $75.2 \%$ of respondents were satisfied or very satisfied with their MSI success. ${ }^{6}$ In a survey of French orthodontists, $74 \%$ were satisfied with their experience with MSI. ${ }^{10}$ From these results it is apparent that orthodontists are generally satisfied with MSI treatment outcome and this is probably truer in recent years as the profession has narrowed on which types of cases acquires most benefit from skeletal anchorage.

The most commonly used MSI systems in the present study were American orthodontics followed by Ormco and 3M oral care. These manufacturers may be popular because they are large companies that orthodontists might already be using their products.

In our present study soft tissue overgrowth adjacent to miniscrew insertion site was reported by $66.9 \%$ of orthodontists which is higher when compared to the results of a survey by Ahmed Meeran et al. ${ }^{9}$ The studies done by Park HS et al. ${ }^{15}$ and Viwattanatipa $\mathrm{N}$ et al. ${ }^{16}$ have found inflammation and soft tissue overgrowth to be significant risk factors associated with MSI failure.

Among the participants $64.8 \%$ advice special oral hygiene measures such as mouth wash, brushing around implants which plays a vital role in success of MSI as supported by the studies conducted by Kuroda S et al. ${ }^{17}$ Kyung SH et al. ${ }^{18}$ Luzi C et al. ${ }^{19}$ Park HS et al. ${ }^{20}$

\section{MSI Complications}

Among the participants, $32.8 \%$ of orthodontists experienced same failure rate of MSI in maxilla and mandible. This result wasin agreement with the studies by Moon $\mathrm{CH}$ et al.21 Antoszewska J et al. ${ }^{22}$ Lim HJ et al. ${ }^{23} \mathrm{Kim}$ SH et al. ${ }^{24}$

Majority of the participants (37.6\%) reported with the failure rate of $10-25 \%$ which was in accordance with the study done by Bayat and Bauss et al. ${ }^{25}$ Bechtold et al. ${ }^{26}$ Hedayati et al. ${ }^{27}$ and Motoyoshi et al. ${ }^{12}$ followed by $25-50 \%$ of failure rate by $28.3 \%$ of respondents as supported by the study by Sarul et al. ${ }^{28}$ Herman et al. ${ }^{29}$

The clinical problem associated with MSI failure given by Indian orthodontists was loosening of the screw (50.3\%), which was similar to the results of the study done by Hyde JD et al. ${ }^{7}$ among American orthodontists and a systematic review by Reynders R. ${ }^{30}$ The major drawback while using miniscrews appeared to be failure due to miniscrew loosening even with the orthodontists having more clinical experience and have been placing implants for more than 5 years. The reason for MSI loosening appears to be multifactorial and is a disconcerting and unpredictable reality which we have to 
embrace in our clinical practice as supported by the study done by Cheng SJ et al. ${ }^{31}$

In our survey, pain and discomfort in the insertion site have been a reason for removal of MSI in 20.6\%. In a study conducted by Kuroda et al. $3235 \%$ of patient experience pain even after one week when placed by flap method.

\section{CONCLUSIONS}

There has been an increase in the usage of MSI among the Indian orthodontists, which clearly indicates increased awareness of MSI. The knowledge and experience about the MSI among the Indian orthodontists in insertion torque, force application and oral hygiene measures were in accordance with recent global trends. Most orthodontists prefer American orthodontics followed by Ormco and $3 \mathrm{M}$ oral care titanium MSI. Failure rate experienced by Indian orthodontists was similar to orthodontists practicing globally and the main reason for MSI failure may be due to soft tissue overgrowth. As experience increases, the decision is made on clinical situation when there was an MSI failure and the degree of satisfaction with MSI post treatment outcome increased to 'very satisfied'.

Data sharing statement provided by the authors is available with the full text of this article at jemds.com.

Financial or other competing interests: None.

Disclosure forms provided by the authors are available with the full text of this article at jemds.com.

\section{REFERENCES}

[1] Cope JB. Temporary anchorage devices in orthodontics: a paradigm shift. Semin Orthod 2005;11(1):3-9.

[2] Creekmore TD, Eklund MK. The possibility of skeletal anchorage. J Clin Orthod 1983;17(4):266-9.

[3] Kanomi R. Mini-implant for orthodontic anchorage. J Clin Orthod 1997;31(11):763-7.

[4] Papadopoulos MA, Tarawneh F. The use of miniscrew implants for temporary skeletal anchorage in orthodontics: a comprehensive review. Oral Surg Oral Med Oral Path Oral Radiol Endod 2007;103(5):e6-15.

[5] Keim RG, Gottlieb EL, Nelson AH, et al. 2008 JCO study of orthodontic diagnosis and treatment procedures, part 1: results and trends. J Clin Orthod 2008;42(11):625-40.

[6] Buschang PH, Carrillo R, Ozenbaugh B, et al. 2008 survey of AAO members on miniscrew usage. J Clin Orthod 2008;42(9):513-8.

[7] Hyde JD, King GJ, Greenlee GM, et al. Survey of orthodontists attitudes and experiences regarding miniscrew implants. J Clin Orthod 2010;44(8):481-6.

[8] Shetty SK, Haris E, Vijayananda KM, et al. Current trend in mini implants usage among South Indian Orthodontics. International Journal of Scientific Development and Research 2019;4(3):311-7.

[9] Meeran NA, Venkatesh KG, Parveen MFJ. Current trends in miniscrew utilization among Indian Orthodontists. J Orthod Sci 2012;1(2):46-50.
[10] Barthelemi S, Beauval $H$. Prevalence of the use of anchorage miniscrews among French Orthodontists. Int Orthod 2015;13(4):436-61.

[11] Morea C, Dominguez GC, Valle Wuo AD, et al. Surgical guide for optimal positioning of mini-implants. J Clin Orthod 2005;39(5):317-21.

[12] Motoyoshi M, Yoshida T, Ono A, et al. Effect of cortical bone thickness and implant placement torque on stability of orthodontic mini-implants. Int J Oral Maxillofac Implants 2007;22(5):779-84.

[13] Chen Y, Kang ST, Bae SM, et al. Clinical and histologic analysis of the stability of microimplants with immediate orthodontic loading in dogs. Am J Orthod Dentofacial Orthop 2009;136(2):260-7.

[14] Jambi S, Walsh T, Sandler J, et al. Reinforcement of anchorage during orthodontic brace treatment with implants or other surgical methods. Cochrane Database Syst Rev 2014;2014(8):CD005098.

[15] Park HS, Lee SK, Kwon OW. Group distal movement of teeth using microscrew implant anchorage. Angle Orthod 2005;75(4):602-9.

[16] Viwattanatipa N, Thanakitcharu S, Uttraravichien A, et al. Survival analyses of surgical miniscrews as orthodontic anchorage. Am J Orthod Dentofacial Orthop 2009;136(1):29-36.

[17] Kuroda S, Sugawara Y, Deguchi T, et al. Clinical use of miniscrew implants as orthodontic anchorage: success rates and postoperative discomfort. Am J Orthod Dentofacial Orthop 2007;131(1):9-15.

[18] Kyung SH, Choi HW, Kim KH, et al. Bonding orthodontic attachments to miniscrew heads. J Clin Orthod 2005;39(6):348-53.

[19] Luzi C, Verna C, Melsen B. Guidelines for success in placement of orthodontic miniimplants. J Clin Orthod 2009;43(1):39-44.

[20] Park HS, Jeong SH, Kwon OW. Factors affecting the clinical success of screw implants used as orthodontic anchorage. Am J Orthod Dentofacial Orthop 2006;130(1):18-25.

[21] Moon CH, Lee DG, Lee HS, et al. Factors associated with the success rate of orthodontic miniscrews placed in the upper and lower posterior buccal region. Angle Orthod 2008;78(1):101-6.

[22] Antoszewska J, Papadopoulos MA, Park HS, et al. Five-year experience with orthodontic miniscrew implants: a retrospective investigation of factors influencing success rates. Am J Orthod Dentofacial Orthop 2009;136(2):158.e1-10.

[23] Lim HJ, Eun CS, Cho JH, et al. Factors associated with initial stability of miniscrews for orthodontic treatment. Am J Orthod Dentofacial Orthop 2009;136(2):236-42.

[24] Kim SH, Lee SJ, Cho IS, et al. Rotational resistance of surface-treated mini-implants. Angle Orthod 2009;79(5):899-907.

[25] Bayat E, Bauss O. Effect of smoking on the failure rates of orthodontic miniscrews. J Orofac Orthop 2010;71(2):11724.

[26] Bechtold TE, Kim JW, Choi TH, et al. Distalization pattern of the maxillary arch depending on the number of orthodontic miniscrews. Angle Orthod 2013;83(2):26673. 
[27] Hedayati Z, Hashemi SM, Zamiri B, et al. Anchorage value of surgical titanium screws in orthodontic tooth movement. Int J Oral Maxillofac Surg 2007;36(7):588-59.

[28] Sarul M, Minch L, Park HS, et al. Effect of the length of orthodontic mini-screw implants on their long-term stability: a prospective study. Angle Orthod 2015;85(1):33-8.

[29] Herman RJ, Currier GF, Miyake A. Mini-implant anchorage for maxillary canine retraction: a pilot study. Am J Orthod Dentofacial Orthop 2006;130(2):228-35.
[30] Reynders R, Ronchi L, Bipat S. Mini-implants in orthodontics: a systematic review of the literature. Am J Orthod Dentofacial Orthop 2009;135(5):564.e1-19.

[31] Cheng SJ, Tseng IY, Lee JJ, et al. A prospective study of the risk factors associated with failure of mini-implants used for orthodontic anchorage. Int J Oral Maxillofac Impl 2004;19(1):100-6.

[32] Kuroda S, Tanaka E. Risks and complications of miniscrew anchorage in clinical orthodontics. Japanese Dental Science Review 2014;50(4):79-85. 